\title{
The Carers' Needs Assessment for Dementia (CNA-D): a validation study in the Italian population
}

\author{
Milena Zucca ${ }^{1}$ (D) Elisa Rubino ${ }^{2}$ - Alessandro Vacca ${ }^{1}$ - Paola De Martino ${ }^{1} \cdot$ Marcella Caglio $^{1} \cdot$ Andrea Marcinnó $^{1}$. \\ Mario $\mathrm{Bo}^{3} \cdot$ Innocenzo Rainero ${ }^{1}$
}

Received: 18 January 2021 / Accepted: 22 April 2021 / Published online: 4 May 2021

(C) The Author(s) 2021

\begin{abstract}
Background Dementia has devastating consequences for families with important physical, psychological, social, and financial effects. Evaluation of caregiver's needs may be an important step to reduce the burden of family caregivers of dementia patients. An Austrian scale, the Carers' Needs Assessment for Dementia, is now available for measuring the caregiver's needs. The aim of our study was to evaluate the psychometric properties of the Italian version of the CNA-D (iCNA-D).

Methods A sample of 214 voluntary caregivers of dementia patients was recruited at the Department of Neuroscience, University of Turin (Italy). All participants were administered the iCNA-D. Validity and reliability of the instrument were evaluated using Beck Depression Inventory (BDI), Beck Anxiety Inventory (BAI), Symptom Checklist-90 (SCL-90), and the Italian version of Zarit Burden Interview (I-ZBI).

Results The most common unmet need reported for the iCNA-D was "counseling and emotional support" (31.5\%). This item demonstrates adequate reliability with moderate internal consistency for all "summary scores" of iCNA-D $(\alpha \geq 0.75)$ and splithalf correlation of more than 0.80 for two of them. We also found positive correlations in two out of three "summary scores" of iCNA-D and in the overall outcomes of BDI, BAI, SCL-90, and I-ZBI.

Conclusions The iCNA-D could be a valid and reliable tool for a comprehensive assessment of needs and possible social supports proposed to relatives who take care of patients with dementia. Better understanding of family caregivers' needs could improve planning of local services and reduce caregivers' perception of distress and burden.
\end{abstract}

Keywords Caregiver $\cdot$ Dementia $\cdot$ Need assessment $\cdot$ Italian $\cdot$ Validation $\cdot$ CNA-D

\section{Introduction}

With the progressive increase of elderly population, dementia has become a dramatic health and socio-economic problem. In absence of therapeutic strategies capable of even slowing the progression of the syndrome, in 2050, there will be more than 150 million people affected with dementia worldwide [1].

Milena Zucca

milena.zucca@unito.it

1 Department of Neuroscience "Rita Levi Montalcini", Aging Brain and Memory Clinic, University of Torino, Via Cherasco 15, 10126 Turin, Italy

2 Department of Neuroscience and Mental Health, A.O.U. Città della Salute e della Scienza di Torino, Turin, Italy

3 Department of Medical Sciences, Section of Geriatrics, University of Torino, Città della Salute e della Scienza di Torino, Turin, Italy
During its course, dementia has devastating effects also on family members who are involved in patient's care, usually named as "informal caregivers" [2]. It is well recognized that the increasing burden of care along with the progression of dementia has important physical, psychological, social, emotional and financial adverse effects for informal caregivers [3]. Moreover, the increasing frailty of the caregiver may result in an early patient's institutionalization [4, 5].

It has been assumed that the evaluation of caregiver's needs may be an important step for planning social and health services dedicated to caregivers and patients with cognitive impairment [6-8]. Van Haaster et al. [9] suggested an evaluation of needs divided into three different levels of assessment: (1) the problems experienced by patient or caregiver, (2) the interventions necessary to reduce these problems and (3) the services required to make these interventions available.

To the best of our knowledge, the Carers' Needs Assessment for Dementia (CNA-D) [10] is the only scale 
psychometrically robust [11] recommended for research purposes for planning local services [12]. This is in accordance with the suggestions of Van Haaster et al. [9] and, in line with literature [13], involves the perspective of both carers and experts for a more comprehensive assessment of unmet needs of caregivers.

The CNA-D was used by Wancata et al. [10] for evaluation of needs in informal caregivers of patients with a severe cognitive impairment due to Alzheimer's disease. These authors [10] found that the most important problems experienced by caregivers of patients with a severe cognitive impairment were disappointment caused by the illness and concerns about the patient's future (68.9\%). Furthermore, these authors have also highlighted that a number of problems reported by the interviewed caregivers were often not satisfied at all by available supports and services. This result, in line with literature [14], is remarkably interesting because it is recognized that a higher number of unmet needs can increase levels of psychological distress, depression, anxiety and physical impairments $[3,15,16]$.

To date there has not been any validation of this scale on Italian population, yet. The aim of this research is to validate the CNA-D in an Italian population of caregivers of patients affected by the most common forms of dementias and with different degrees of cognitive and functional abilities impairment.

\section{Methods}

\subsection{Sample and setting}

Two hundred and fourteen caregivers $(\mathrm{M} / \mathrm{F}=72 / 142$; mean age $\pm \mathrm{SD}=64 \pm 13$ years) of patients with a previously established primary diagnosis of major neurodegenerative disorder (i.e., Alzheimer's disease (AD), frontotemporal dementia (FTD), vascular dementia (VaD), and dementia with Lewy bodies (DLB)) were recruited on voluntary basis at the Department of Neuroscience, University of Torino (Italy). Participants were included in the study if they were the principal caregiver of a patient with a primary diagnosis of dementia. Relatives were excluded from the study if they had a history of severe cognitive impairment or mental illness. The family caregivers' interviews were conducted by a trained psychologist in different settings, including outpatient clinics, day centers, and inpatient and residential care. The relatives were interviewed in person, by phone or via Skype platform.

\subsection{Measurements and instruments}

In our study, we considered only the demographic and clinical data acquired in no more than three months before the date of the interview. Degree of cognitive impairment was assessed according to the most recent patient's raw scores at the Italian version of Mini Mental State Examination (MMSE) [17], at the Clinical Dementia Rating Scale (CDR) [18] or at the Short Portable Mental Status Questionnaire (SPMSQ) [19]. Patients were then divided into three subgroups: (1) patients with mild cognitive deficit; (2) patients with a moderate cognitive deficit, and (3) patients with a severe cognitive deficit [20].

Functional status of patients was assessed with the Activities of Daily Living scale (ADL) [21] and the Instrumental Activities of Daily Living scale (IADL) [22] that were administered to caregivers during the interview. Patients were divided again in three subgroups: 1) patients completely autonomous or only partially dependent; 2 ) moderately dependent patients and 3) patients completely dependent [20].

Caregivers were interviewed with an Italian version of CNA-D, a semi-structured questionnaire that investigates the problems found by each subject in the caring of patient in the three months before the interview. The CNA-D includes a total of 20 problem areas: 18 predefined problem areas in the main interview related to the principal social, emotional, and practical needs perceived from caregivers, an additional $19^{\text {th }}$ area for the assessment of possible additional problems experienced by caregiver (not mentioned in the main interview).

A separate problem area is used only in case of a recent onset of the disease. Problem severity is rated on a threepoint scale: no or mild problem; moderate problem; serious problem. For each problem with a severity degree between moderate to serious, referred by the caregiver and/or the expert, CNA-D scale offers two to six different interventions, including an additional item called "other intervention" referring to supports which are not present in the previous helps list.

Caregivers and experts rated each intervention using a fivepoint scale, as summarized below:

$0=$ "no need": if the intervention was not needed and not received;

1 = "overprovision": if the intervention was not needed, but received;

2 = "unmet need": if intervention was needed, but not received;

3 = "partially met need": if the intervention was needed and insufficiently received;

$4=$ "met need": if the intervention was needed and sufficiently received.

Where selection of supports is concerned, the authors underline that only the most appropriate help to solve a given problem is usually rated as "needed intervention." Occasionally, more supports can be marked as need, only if a problem area can be ameliorated with a combination of several interventions simultaneously. 
The psychometric properties of the CNA-D can be viewed in the original article of Wancata et al. [10]. Authors reported an internal consistency (Cronbach's $\alpha$ coefficient) of .70 for the "summary score" of problems, of .95 for the "summary scores" of met needs and of .88 for the "summary scores" of unmet needs according to the caregiver's evaluation. The Cronbach's $\alpha$ coefficient for the interviewers' ratings, instead, were reported to be $.72, .96$ and .90 . Furthermore, the estimation of instrument validity [10] reported a positive correlation between the total score of Zarit Burden Inventory (ZBI) [23] and the number of moderate or serious problems both marked by relatives $(r=.683)$ and experts $(r=.673)$. Finally, the carers' burden was positively correlate with "summary scores" of unmet needs (carers: $r=.523$, experts: $r=.502$ ), and negatively associated with "summary scores" of met needs (carers: $r=-.333$, experts: $r=-.456$ ).

Three Italian researchers (MZ, AV, ER) independently translated the original English version of CNA-D [10] into Italian. All versions were compared to produce a draft which was translated into English by an additional researcher (PD) and finally compared with the original English version.

To test the psychometric properties of the Italian version of CNA-D, caregivers were administered specific questionnaires evaluating subjective burden degree, psychological distress and emotional situation of caregivers: the Italian version of ZBI (I-ZBI) [24], the Symptom Checklist-90-Revised (SCL90-R) [25], the Beck Depression Inventory (BDI) [26], the Beck Anxiety Inventory (BAI) [27], and the Apathy Evaluation Scale-Clinician Version (AS) [28].

We chose these specific instruments because social burden, psychological distress and emotional status dimensions are reported to be related to the presence of a higher number of caregivers' problems and unmet needs [29]. The validation protocol was preliminary administrated to forty caregivers of patients with dementia.

\subsection{Data analysis}

All data were analyzed using SPSS version 21.0 for Windows (IBM SPSS Statistics, Inc., Chicago, Illinois). The significance level was set at $p<.05$ for all analyses. Demographic and clinical characteristics of caregivers and patients are presented as frequencies and percentages. Cronbach's $\alpha$ coefficient and the split-half correlation were used to calculate the relation among the "summary scores" of the iCNA-D. In detail Cronbach's $\alpha$ coefficient evaluates internal consistency in relation with the average correlation between items, while split-half correlation, a measure of reliability, is a comparison between even and odd items of each abovementioned "summary score." To analyze the construct validity, we performed a Spearman's correlations between the three "summary scores" of the iCNA-D and the sum-score of the I-ZBI,
SCL-90-R, BDI, BAI, and AS. In addition, subscales' scores of SCL-90-R were included in the correlation analysis.

\section{Results}

\subsection{Characteristics of the sample}

The demographic and clinical characteristics of patients and caregivers are shown in Table 1 . In our study, $142(66 \%)$ of recruited caregivers were women, half spouse $(104 ; 49 \%)$ and half children $(102 ; 48 \%)$ of patients, while $3 \%$ of caregivers were grandchildren. The mean age of the sample was $64 \pm 13$ years. About $62 \%$ of relatives involved in the study lived with patients and the majority had a private home care support $(68 \%)$ more often given by other family caregiver $(44.1 \%)$. Mean of years schooling in our sample was $12 \pm 4$ years, with most of the caregivers having a high school education (42\%). The majority of patients had a diagnosis of $\mathrm{AD}(61 \%)$ and a severe cognitive impairment (47\%). ADL and IADL had mean values respectively of $3.62 \pm 2.06$ and $2.57 \pm 2.61$.

The percentage of the problems evaluated as moderate or serious by caregivers and interviewers are summarized in Table 2. The most frequent problem for subjects providing direct care to patients with dementia was "disappointment caused by the illness, concerns about the patient's future" $(57.9 \%)$. The interventions selected by caregivers and experts are summarized in Table 3. As reported by Wancata et al. [10], although during the interview identical interventions were presented and evaluated separately for each problem area, during the analysis similar intervention were merged to avoid redundancies.

The intervention more often reported as necessary by caregivers was "financial compensation" (53.9\%), while that most common unmet need, according to the caregivers and interviewers, was "counseling and emotional support" (31.5\%). In our sample, relatives and experts reported that the "financial compensation" is often a partially $(23.7 \%)$ or completely $(13.2 \%)$ met need. Very rarely an intervention was evaluated by caregivers or interviewers as "overly given." The mean total scores of I-ZARIT, SCL-90, BDI, BAI, and AS were $21.75 \pm 18.52,22.33 \pm 20.47,6.22 \pm 5.06,7.25 \pm 6.10$, and $5.49 \pm 5.83$, respectively.

\subsection{Reliability and validity}

Concerning the reliability analysis, Cronbach's $\alpha$ coefficient was .79 for the "summary score" of problems, .75 for the "summary score" of met needs, and .78 for "summary score" of unmet needs reported by the caregivers. The "summary scores" of problems, of met and unmet needs according to the interviewers' ratings generated $\alpha$ coefficients of .79, of .75 , and of .77 , respectively. The split-half correlation 
Table 1 Synopsis of the demographic and clinic characteristics of patients and caregivers
Value and percentage $(N(\%))$

Mean $( \pm \mathrm{SD})$ years

Caregiver characteristics; $N=214$

Sex
Male
Female
Age
$\geq 65$ years
$<65$ years
Education
Primary
Secondary
High
University
Relationship with patient
Spouse
Children
Others
Care support
No
Yes
Care for the patient by an informal caregiver
Care for the patient in a day center
Care for the patient by a formal caregiver
Patient characteristics; $N=214$
Diagnosis
AD
VaD
FTD
DLB
Cognitive status
No or mild cognitive impairment
Moderate cognitive impairment
Severe cognitive impairment
Functional status
ADL
No or mild impairment
Moderate impairment
Severe impairment
IADL
No or mild impairment
Moderate impairment
Severe impairment

$72(34 \%)$

$142(66 \%)$

$109(51 \%)$

$105(49 \%)$

$27(13 \%)$

$69(32 \%)$

$89(42 \%)$

$29(14 \%)$

$104(49 \%)$

$102(48 \%)$

$8(3 \%)$

$69(32 \%)$

$145(68 \%)$

$64(44.1 \%)$

$47(32.4 \%)$

$34(23.4 \%)$

$131(61 \%)$

$45(21 \%)$

$30(14 \%)$

$8(4 \%)$

$46(21 \%)$

$68(32 \%)$

$100(47 \%)$

$118(55 \%)$

$77(36 \%)$

$19(9 \%)$

$49(23 \%)$

$100(47 \%)$

$65(30 \%)$
$64 \pm 13$

$12 \pm 4$

$A D$, Alzheimer's disease; $F T D$, frontotemporal dementia; $V a D$, vascular dementia; $D L B$, dementia with Lewy bodies; $A D L$, activities of daily living; $I A D L$, instrumental activities of daily living

coefficient was .84 for the "summary score" of problems, .62 for the "summary score" of met needs and .86 for "summary score" of unmet needs reported by the relievers. A slit-half correlation coefficient of .84 , of .62 , and .85 was obtained by the "summary score" of problems, of met needs, and of unmet needs according to the experts' evaluations.

Regarding the validity analysis the Spearman's correlation showed a significant positive correlation between the iCNA-D 
Table 2 Percentages of problems evaluated as moderate or serious by caregivers and interviewers

\begin{tabular}{|c|c|c|}
\hline & Carer $(\%)$ & Interviewer $(\%)$ \\
\hline Lack of information about dementia & 30.8 & 30.8 \\
\hline Lack of information about treatment & 21.5 & 21.5 \\
\hline Lack of information about services & 25.7 & 25.7 \\
\hline Financial burden & 35.0 & 35.0 \\
\hline Legal issues & 15.4 & 15.4 \\
\hline Disappointment caused by the illness, concerns about the patient's future & 57.5 & 57.9 \\
\hline Communication problems and conflicts with the patient & 51.9 & 51.9 \\
\hline Burdened by behavioral problems of the patients & 38.3 & 38.3 \\
\hline Problems caused by crises & 19.2 & 19.6 \\
\hline Not enough time for oneself (including caring for the patient when the relative becomes sick) & 53.3 & 52.8 \\
\hline Social isolation, conflicts within the family & 36.0 & 36.0 \\
\hline Burden caused by dangerous situations & 37.4 & 37.4 \\
\hline Fear of stigmatization and discrimination & 12.1 & 12.6 \\
\hline Feelings of guilt, being blamed & 17.3 & 17.8 \\
\hline Missing nursing skills & 15.9 & 15.9 \\
\hline Difficulties concerning household tasks & 37.9 & 37.9 \\
\hline Burned out or overstrained by care & 45.3 & 45.8 \\
\hline Physical or psychiatric illness of the carer & 45.3 & 46.3 \\
\hline Others & 0.0 & 0.0 \\
\hline
\end{tabular}

"summary score" of problems and unmet needs reported by the caregivers and experts and the total score of I-ZBI $(p<.01)$ and of SCL-90-R $(p<.01)$. Furthermore, we also found that the iCNA-D "summary score" of problems and unmet needs indicated by the relatives and interviewers was positively related to subscales of SCL-90 $(p<.05)$ and the total score of BDI $(p<.01)$ and BAI $(p<.01)$. Finally, the iCNA-D "summary score" of met needs was negatively associated with total score of I-ZBI (caregivers: $p=.043$, interviewers: $p=.047$ ) and "paranoid ideation" subscale of SCL-90 (caregivers: $p=$ .012 , interviewers: $p=.011$ ) (Table 4).

\section{Discussion}

The main purpose of our study was to evaluate reliability and validity of the Italian version of CNA-D and our data showed that iCNA-D has an adequate internal consistency, in particular for "summary score" of problems and unmet needs evaluated by both caregivers and specialists. Regarding "summary score" of met needs according to caregivers' and experts' evaluations, we found a Cronbach's $\alpha$ equal to .75 in both cases, while the split-half correlation coefficient is .62. In our study, summary score of problems and unmet needs, obtained from the assessment of both caregivers and experts, positively and significantly correlates with total score of I$\mathrm{ZBI}$ and BAI. A positive correlation was also found with the subscales of SCL-90. "Summary score" of met needs was, instead, negatively associated with total score of I-ZBI and "paranoid ideation" subscale of SCL-90. These results support the concurrent validity of the iCNA-D. Particularly, the existence of a strong positive correlation between total score of IZBI and "summary score" of problems and unmet needs confirm the hypothesis of other studies $[3,10]$, reporting that the presence of a greater number of problems, not solved or only partially solved, can increase the subjective burden experienced by caregivers. Furthermore, in our sample, if problems were associated with a higher number of unmet needs, it was also possible to find a major level of depression, anxiety, and other psychological symptom dimensions, such as somatization, obsessive-compulsive features, interpersonal sensitivity, hostility, phobic anxiety, paranoid ideation, and sleep disturbance. In contrast, the presence of met needs seemed to decrease the level of burden perceived by the subject and, intriguingly, seemed also to reduce psychological symptoms as projective thinking, hostility, suspicion, fear of loss of autonomy etc.

Our data are supported by other researches [15, 16, 29] in which a correlation was reported between the presence of unmet needs and an increase of subject's psychological distress. In our study, caregivers reported the "financial compensation" as the most necessary intervention (53.9\%) and simultaneously the most often partially $(23.7 \%)$ or completely (13.2\%) "met need," while the lack of personal time is the second most frequently problem complained by caregivers during the interview (53.3\%). Additionally, although the 
Table 3 Percentages of interventions selected by caregivers and experts as most appropriate for solving one or more problems

\begin{tabular}{|c|c|c|c|c|c|c|}
\hline & & $\begin{array}{l}\text { No need } \\
(\%)\end{array}$ & $\begin{array}{l}\text { Overprovision } \\
(\%)\end{array}$ & $\begin{array}{l}\text { Unmet need } \\
(\%)\end{array}$ & $\begin{array}{l}\text { Partially met } \\
\text { need }(\%)\end{array}$ & $\begin{array}{l}\text { Met need } \\
(\%)\end{array}$ \\
\hline \multirow[t]{2}{*}{ Counseling and emotional support } & Carer & 59.4 & 0.1 & 31.5 & 6.0 & 3.0 \\
\hline & Interviewer & 59.0 & 0.1 & 32.0 & 5.9 & 3.0 \\
\hline \multirow[t]{2}{*}{ Relatives group guided by a professional } & Carer & 93.1 & 0.0 & 4.1 & 1.8 & 1.0 \\
\hline & Interviewer & 93.2 & 0.0 & 4.0 & 1.8 & 1.0 \\
\hline \multirow[t]{2}{*}{ Self-help group for family members } & Carer & 94.8 & 0.1 & 2.5 & 1.1 & 1.5 \\
\hline & Interviewer & 94.9 & 0.1 & 2.5 & 1.1 & 1.5 \\
\hline \multirow[t]{2}{*}{ Individual psychoeducation } & Carer & 48.5 & 0.0 & 28.3 & 21.4 & 1.7 \\
\hline & Interviewer & 48.8 & 0.0 & 28.2 & 21.3 & 1.7 \\
\hline \multirow[t]{2}{*}{ Printed information material } & Carer & 96.9 & 0.0 & 2.3 & 0.8 & 0.0 \\
\hline & Interviewer & 96.9 & 0.0 & 2.3 & 0.8 & 0.0 \\
\hline \multirow[t]{2}{*}{ Support from a social worker } & Carer & 49.3 & 0.0 & 29.0 & 12.2 & 9.5 \\
\hline & Interviewer & 49.3 & 0.0 & 29.0 & 12.2 & 9.5 \\
\hline \multirow[t]{2}{*}{ Group psychoeducation } & Carer & 80.4 & 0.0 & 12.3 & 5.2 & 2.1 \\
\hline & Interviewer & 80.4 & 0.0 & 12.3 & 5.2 & 2.1 \\
\hline \multirow[t]{2}{*}{ Financial compensation } & Carer & 44.7 & 1.3 & 17.1 & 23.7 & 13.2 \\
\hline & Interviewer & 44.7 & 1.3 & 17.1 & 23.7 & 13.2 \\
\hline \multirow[t]{2}{*}{ Temporary supervision of the patient at home } & Carer & 65.4 & 0.0 & 26.3 & 6.4 & 1.8 \\
\hline & Interviewer & 66.2 & 0.0 & 25.9 & 6.1 & 1.8 \\
\hline \multirow[t]{2}{*}{ Care for the patient in a day center } & Carer & 56.5 & 0.0 & 13.9 & 19.6 & 10.0 \\
\hline & Interviewer & 56.8 & 0.0 & 13.6 & 19.6 & 10.1 \\
\hline \multirow[t]{2}{*}{ Mobile personal care for outpatients } & Carer & 74.6 & 0.0 & 14.4 & 6.7 & 4.3 \\
\hline & Interviewer & 74.3 & 0.0 & 14.7 & 6.7 & 4.3 \\
\hline \multirow{2}{*}{$\begin{array}{l}\text { Training of practical skills for the carer (e.g., basic nursing } \\
\text { skills) }\end{array}$} & Carer & 97.5 & 0.0 & 2.1 & 0.4 & 0.0 \\
\hline & Interviewer & 97.1 & 0.0 & 2.1 & 0.4 & 0.4 \\
\hline \multirow[t]{2}{*}{ Diagnosis or treatment of the carer by a GP } & Carer & 84.5 & 0.5 & 4.6 & 6.2 & 4.1 \\
\hline & Interviewer & 84.3 & 0.5 & 5.1 & 6.1 & 4.0 \\
\hline \multirow[t]{2}{*}{ Mobile nursing care for outpatients } & Carer & 71.1 & 0.0 & 12.0 & 9.5 & 7.4 \\
\hline & Interviewer & 71.1 & 0.0 & 12.0 & 9.5 & 7.4 \\
\hline \multirow[t]{2}{*}{ Holidays together with the patient in a specialized setting } & Carer & 100.0 & 0.0 & 0.0 & 0.0 & 0.0 \\
\hline & Interviewer & 100.0 & 0.0 & 0.0 & 0.0 & 0.0 \\
\hline \multirow[t]{2}{*}{ Respite care } & Carer & 96.4 & 0.0 & 2.7 & 0.9 & 0.0 \\
\hline & Interviewer & 96.5 & 0.0 & 2.6 & 0.9 & 0.0 \\
\hline \multirow[t]{2}{*}{ General assistance for household chores } & Carer & 51.2 & 0.0 & 29.6 & 9.9 & 9.3 \\
\hline & Interviewer & 51.2 & 0.0 & 29.6 & 9.9 & 9.3 \\
\hline \multirow[t]{2}{*}{ Hotline, where the carer can get advice in crises } & Carer & 73.2 & 0.0 & 19.5 & 4.9 & 2.4 \\
\hline & Interviewer & 73.8 & 0.0 & 19.0 & 4.8 & 2.4 \\
\hline \multirow[t]{2}{*}{ Psychotherapy } & Carer & 68.5 & 0.0 & 27.0 & 3.1 & 1.4 \\
\hline & Interviewer & 68.7 & 0.0 & 26.9 & 3.0 & 1.3 \\
\hline \multirow[t]{2}{*}{ Social contact service } & Carer & 98.7 & 0.0 & 1.3 & 0.0 & 0.0 \\
\hline & Interviewer & 98.7 & 0.0 & 1.3 & 0.0 & 0.0 \\
\hline \multirow[t]{2}{*}{ Mobile crisis service visiting the family at home } & Carer & 63.4 & 0.0 & 31.7 & 4.9 & 0.0 \\
\hline & Interviewer & 59.5 & 0.0 & 35.7 & 4.8 & 0.0 \\
\hline Specialized services to help with specific household tasks (e.g., & Carer & 97.5 & 0.0 & 1.2 & 1.2 & 0.0 \\
\hline laundry service) & Interviewer & 97.5 & 0.0 & 1.2 & 1.2 & 0.0 \\
\hline Meals-on-wheels & Carer & 98.8 & 0.0 & 1.2 & 0.0 & 0.0 \\
\hline & Interviewer & 98.8 & 0.0 & 1.2 & 0.0 & 0.0 \\
\hline Initiating to become a legal administrator & Carer & 66.7 & 0.0 & 18.2 & 12.1 & 3.0 \\
\hline & Interviewer & 66.7 & 0.0 & 18.2 & 12.1 & 3.0 \\
\hline
\end{tabular}


Table 4 Correlations of caregivers' "summary scores" of iCNA-D with other assessment tools. I-ZBI, Italian version of the Zarit Burden Interview; $S C L-90-R$, Symptom Checklist 90-Revised; BDI, Beck Depression Inventory; BAI, Beck Anxiety Inventory; AS, Apathy Evaluation Scale

\begin{tabular}{|c|c|c|c|c|}
\hline & & "Summary score" of problems & "Summary scores" of met needs & "Summary scores" of unmet needs \\
\hline \multirow[t]{2}{*}{ I-ZBI (total score) } & Carer & $0.731^{* *}$ & $-0.138^{*}$ & $0.819^{* *}$ \\
\hline & Interviewer & $0.736^{* *}$ & $-0.136^{*}$ & $0.828^{* *}$ \\
\hline \multirow{2}{*}{$\begin{array}{l}\text { SCL-90-R } \\
\text { Global Symptom Index }\end{array}$} & Carer & $0.649^{* *}$ & 0.004 & $0.654^{\text {*** }}$ \\
\hline & Interviewer & $0.659^{* *}$ & 0.008 & $0.666^{* *}$ \\
\hline \multirow{2}{*}{$\begin{array}{l}\text { SCL-90-R } \\
\text { Somatization }\end{array}$} & Carer & $0.375^{* *}$ & -0.022 & $0.385^{* *}$ \\
\hline & Interviewer & $0.385^{* *}$ & -0.019 & $0.397^{* * *}$ \\
\hline \multirow{2}{*}{$\begin{array}{l}\text { SCL-90-R } \\
\text { Obsessive compulsive }\end{array}$} & Carer & $0.449^{* *}$ & 0.022 & $0.441^{\text {*** }}$ \\
\hline & Interviewer & $0.461^{* * *}$ & 0.025 & $0.449^{* * *}$ \\
\hline \multirow{2}{*}{$\begin{array}{l}\text { SCL-90-R } \\
\text { Interpersonal sensitivity }\end{array}$} & Carer & $0.423^{* *}$ & -0.121 & $0.459^{* *}$ \\
\hline & Interviewer & $0.430^{* *}$ & -0.116 & $0.468^{* * *}$ \\
\hline \multirow{2}{*}{$\begin{array}{l}\text { SCL-90-R } \\
\text { Depression }\end{array}$} & Carer & $0.702^{* *}$ & 0.089 & $0.680^{* *}$ \\
\hline & Interviewer & $0.708^{* *}$ & 0.092 & $0.689^{* *}$ \\
\hline \multirow{2}{*}{$\begin{array}{l}\text { SCL-90-R } \\
\text { Anxiety }\end{array}$} & Carer & $0.545^{* *}$ & -0.081 & $0.561^{\text {*** }}$ \\
\hline & Interviewer & $0.552^{* *}$ & -0.077 & $0.572^{* *}$ \\
\hline \multirow{2}{*}{$\begin{array}{l}\text { SCL-90-R } \\
\text { Hostility }\end{array}$} & Carer & $0.371^{* *}$ & -0.078 & $0.400^{\text {*** }}$ \\
\hline & Interviewer & $0.376^{* *}$ & -0.790 & $0.408^{* *}$ \\
\hline \multirow{2}{*}{$\begin{array}{l}\text { SCL-90-R } \\
\text { Phobic anxiety }\end{array}$} & Carer & $0.154^{*}$ & -0.078 & $0.186^{\text {*** }}$ \\
\hline & Interviewer & $0.154^{*}$ & -0.077 & $0.185^{* *}$ \\
\hline \multirow{2}{*}{$\begin{array}{l}\text { SCL-90-R } \\
\text { Paranoid ideation }\end{array}$} & Carer & $0.340^{* * *}$ & $-0.172^{*}$ & $0.387^{\text {** }}$ \\
\hline & Interviewer & $0.339^{* *}$ & $-0.173^{*}$ & $0.386^{* *}$ \\
\hline \multirow{2}{*}{$\begin{array}{l}\text { SCL-90-R } \\
\text { Psychoticism }\end{array}$} & Carer & $0.313^{* *}$ & -0.075 & $0.321^{\text {*** }}$ \\
\hline & Interviewer & $0.314^{* *}$ & -0.077 & $0.321^{\text {*** }}$ \\
\hline \multirow{2}{*}{$\begin{array}{l}\text { SCL-90-R } \\
\text { Sleep disturbances }\end{array}$} & Carer & $0.311^{* *}$ & -0.075 & $0.339^{\text {*** }}$ \\
\hline & Interviewer & $0.321^{* * *}$ & -0.071 & $0.351^{\text {** }}$ \\
\hline \multirow[t]{2}{*}{ BDI } & Carer & $0.614^{* *}$ & 0.010 & $0.609^{* *}$ \\
\hline & Interviewer & $0.621^{* * *}$ & 0.012 & $0.616^{\text {*** }}$ \\
\hline \multirow[t]{2}{*}{ BAI } & Carer & $0.496^{* *}$ & -0.060 & $0.517^{* * *}$ \\
\hline & Interviewer & $0.503^{* *}$ & -0.055 & $0.526^{* *}$ \\
\hline \multirow[t]{2}{*}{ AS } & Carer & $0.261^{* *}$ & 0.019 & $0.220^{* * *}$ \\
\hline & Interviewer & $0.258^{\text {*** }}$ & 0.023 & $0.218^{* * *}$ \\
\hline
\end{tabular}

${ }^{*} p<0.05 ;{ }^{* *} p<0.01$

$68 \%$ of relievers received care support, only the $23.4 \%$ of them gets help from a formal caregiver. These findings, in line with other researches $[3,30]$, can be partially explained by the fact that caregivers of our sample tend not to use financial compensations to afford additional care assistance given by a formal caregiver or other similar territorial services.

In this regard, it was suggested that there are four dimensions that can affect decisions of caregivers of patients with dementia to use or refuse available services: service, personal, experiential, and relational factors [31]. In particular, it was speculated that a specific personal factor, the caregivers' lack of acknowledgement of their unmet needs for help, can be associated to a lower utilization of services [32]. Furthermore, Zwingmann et al. [33] have recently highlighted that caregivers' accession rate of support services can be related to the type of help offered. These suggestions further highlight the importance of having an available and specific tool for a comprehensive caregivers' needs assessment.

The most frequently unmet need reported by carers in our study was "counseling and emotional support" (31.5\%). This result is confirmed by past literature evidence [34-36] reporting that a very few informal caregivers of patients with dementia receive counseling and emotional support services. Very often the only emotional support comes from other family members and this can increase the level of relieves' burden, negatively affecting the relationship with the patient. Interestingly, in our sample the unmet or only partially met needs have been reported much more frequently than met needs. These frequencies are in line with the findings of Wancata et al. [10]. Since several variables including clinical 
patients' characteristics [37-39] can affect the caregiver's distress, we have decided to include in our study caregivers of subjects with different diagnosis of dementias and cognitive and functional abilities impairment. We hypothesize that this choice could increase predictive capabilities of this tool and make it more usable in the future research.

Our study has some limitations that should be acknowledged. Firstly, in the "Back Translation" phase we have only involved an Italian researcher that is also a bilingual translator. "Back Translation" step is one type of validity check highlighting conceptual errors in the translation. Since the constructs assessed by the CNA-D are essentially culturally shareable, we assume that this limitation does not invalidate the linguistic validation of the instrument. Secondly, pre-test of iCNA-D was performed only by caregivers and we have not used a specific strategy (e.g., cognitive interviews) to conduct a more in-deep pre-test assessment. However, in the original validation study, Wancata et al. [10] had already extensively developed the pre-test phase on both carers and experts. Finally, socio-demographic caregivers' features [40] and clinical patients' characteristics [37-39] that often affect the caregiving burden were not explored widely in this study because it was not the principal aim of our research. However, future studies that will use this tool could more in-deep investigate these dimensions.

\section{Conclusions}

In our study, we evaluated the reliability and validity of the Italian version of CNA-D and we found that this scale could be a valid and reliable tool for a comprehensive assessment of needs and possible social supports proposed to caregivers of patients with dementia. Clarifying the structure of the iCNA$\mathrm{D}$ has potential social and health implications. Better understanding of needs of relatives that assist patients with dementia could improve targeted intervention programs for planning specific local services, with a consecutive reduction of burden and an increase of quality of life for caregivers.

\begin{abstract}
Acknowledgements The authors thank Dr. Wancata who agreed to our proposal for the validation of the CNA-D in the Italian population. MZ received and unrestricted educational grant from UNIPOLSAI. The authors thank the caregivers who participated in this research and the associations "A.S.V.A.D.," "A.I.M.A. Biella," "A.F.M.A. Genova APS," "Alzheimer Monza e Brianza," and the social cooperatives "Nuovo Solco O.N.L.U.S," "Sanitalia Service," "Il Margine A R.L.," and "Gruppo La Villa Spa" for their support.
\end{abstract}

Author contribution M. Zucca, E. Rubino, and I. Rainero were involved in formulating the research question, in designing the study and carrying it out as well as to drafting and critically revising the article, and giving the final approval. M. Zucca, A. Vacca, and A. Marcinnó have contributed to statistical analysis and interpretation of data. M. Caglio, P. De Martino, and M. Bo, were involved in critically revising the article and to final approval.

Funding Open access funding provided by Università degli Studi di Torino within the CRUI-CARE Agreement.

\section{Declarations}

Conflict of interest The authors declare no competing interests.

Ethical approval All procedures were performed in accordance with the local ethics committee and with the ethical standards laid down in the 1964 Declaration of Helsinki and its later amendments.

Informed consent The Local Ethics Committee approved the study protocol. Written informed consent was obtained from all participants.

Open Access This article is licensed under a Creative Commons Attribution 4.0 International License, which permits use, sharing, adaptation, distribution and reproduction in any medium or format, as long as you give appropriate credit to the original author(s) and the source, provide a link to the Creative Commons licence, and indicate if changes were made. The images or other third party material in this article are included in the article's Creative Commons licence, unless indicated otherwise in a credit line to the material. If material is not included in the article's Creative Commons licence and your intended use is not permitted by statutory regulation or exceeds the permitted use, you will need to obtain permission directly from the copyright holder. To view a copy of this licence, visit http://creativecommons.org/licenses/by/4.0/.

\section{References}

1. Alzheimer's Disease International (2019) World Alzheimer Report 2019 - Attitudes to dementia. Alzheimer's Disease International, London

2. Todd S, Barr S, Roberts M, Passmore AP (2013) Survival in dementia and predictors of mortality: a review. Int J Geriatr Psychiatry 28(11):1109-1124. https://doi.org/10.1002/gps.3946

3. Hughes TB, Black BS, Albert M, Gitlin LN, Johnson DM, Lyketsos CG, Samus QM (2014) Correlates of objective and subjective measures of caregiver burden among dementia caregivers: influence of unmet patient and caregiver dementia-related care needs. Int Psychogeriatr 26(11):1875-1883. https://doi.org/10. 1017/S1041610214001240

4. Kelley AS, McGarry K, Gorges R, Skinner JS (2015) The burden of health care costs for patients with dementia in the last 5 years of life. Ann Intern Med 163(10):729-736. https://doi.org/10.7326/M150381

5. Eska K, Graessel E, Donath C, Schwarzkopf L, Lauterberg J, Holle R (2013) Predictors of institutionalization of dementia patients in mild and moderate stages: a 4-year prospective analysis. Dement Geriatr Cogn Dis Extra 3(1):426-445. https://doi.org/10.1159/ 000355079

6. Mansfield E, Boyes AW, Bryant J, Sanson-Fisher R (2017) Quantifying the unmet needs of caregivers of people with 
dementia: a critical review of the quality of measures. Int J Geriatr Psychiatry 32(3):274-287. https://doi.org/10.1002/gps.4642

7. Bangerter LR, Griffin JM, Zarit SH, Havyer R (2019) Measuring the needs of family caregivers of people with dementia: an assessment of current methodological strategies and key recommendations. J Appl Gerontol 38(9):1304-1318. https://doi.org/10.1177/ 0733464817705959

8. Queluz FN, Kervin E, Wozney L, Fancey P, McGrath PJ, Keefe J (2019) Understanding the needs of caregivers of persons with dementia: a scoping review. Int Psychogeriatr 32:35-52. https://doi. org/10.1017/S1041610219000243

9. Van Haaster I, Lesage AD, Cyr M, Toupin J (1994) Problems and needs for care of patients suffering from severe mental illness. Soc Psychiatry Psychiatr Epidemiol 29:141-148. https://doi.org/10. 1007/BF00796495

10. Wancata J, Krautgartner M, Berner J, Alexandrowicz R, Unger A, Kaiser G, Marquart B, Weiss M (2005) The Carers' Needs Assessment for Dementia (CNA-D): development, validity and reliability. Int Psychogeriatr 17:393-406. https://doi.org/10.1017/ S1041610205001699

11. Clemmensen TH, Kristensen HK, Andersen-Ranberg K, Lauridsen HH (2020) Development and field-testing of the Dementia Carer Assessment of Support Needs Tool (DeCANT). Int Psychogeriatr 3:1-13. https://doi.org/10.1017/S1041610220001714

12. Kipfer S, Pihet S (2019) Reliability, validity and relevance of needs assessment instruments for informal dementia caregivers: a psychometric systematic review. JBI Database System Rev Implement Rep. https://doi.org/10.11124/JBISRIR-2017-003976

13. Zwingmann I, Michalowsky B, Esser A, Kaczynski A, Monsees J, Keller A, Hertel J, Wucherer D, Thyrian JR, Eichler T, Kilimann I, Teipel S, Dreier Wolfgramm A, Hoffmann W (2019) Identifying unmet needs of family dementia caregivers: results of the baseline assessment of a cluster-randomized controlled intervention trial. J Alzheimers Dis 67(2):527-539. https://doi.org/10.3233/JAD180244

14. Black BS, Johnston D, Rabins PV, Morrison A, Lyketsos C, Samus QM (2013) Unmet needs of community-residing persons with dementia and their informal caregivers: findings from the maximizing independence at home study. J Am Geriatr Soc 61:2087-2095

15. Stein J, Liegert P, Dorow M, König HH, Riedel-Heller SG (2019) Unmet health care needs in old age and their association with depression-results of a population-representative survey. J Affect Disord 245:998-1006. https://doi.org/10.1016/j.jad.2018.11.096

16. Quail JM, Wolfson C, Lippman A (2011) Unmet need for assistance to perform activities of daily living and psychological distress in community-dwelling elderly women. Can J Aging 30(4):591602. https://doi.org/10.1017/S0714980811000493

17. Measso G, Cavarzeran F, Zappalà G, Lebowitz BD, Crook TH, Pirozzolo FJ, Amaducci LA, Massari D, Grigoletto F (1993) The mini-mental state examination: normative study of an Italian random sample. Dev Neuropsychol 9(2):77-85. https://doi.org/10. 1080/87565649109540545

18. Morris JC, Ernesto C, Schafer K, Coats M, Leon S, Sano M, Thal LJ, Woodbury P (1997) Clinical dementia rating training and reliability in multicenter studies: the Alzheimer's Disease Cooperative Study experience. Neurology 48(6):1508-1510. https://doi.org/10. 1212/wnl.48.6.1508

19. Pfeiffer E (1975) A short portable mental status questionnaire for the assessment of organic brain deficit in elderly patients. J Am Geriatr Soc 23(10):433-441. https://doi.org/10.1111/j.1532-5415. 1975.tb00927
20. De Vresse LP, Bruno P, Giuliani G, Scalori G, Fabbo A (2014) Medico-legal evaluation of dementia: validation of a multidimensional scale. G Gerontol 62:161-171

21. Katz S, Ford AB, Moskowitz RW, Jackson BA, Jaffe MW (1963) Studies of illness in the aged. The index of ADL: a standardized measure of biological and psychosocial function. JAMA 185:914 919. https://doi.org/10.1001/jama.1963.03060120024016

22. Lawton MP, Brody EM (1969) Assessment of older people: selfmaintaining and instrumental activities of daily living. Gerontologist 9(3):179-186

23. Zarit SH, Reever KE, Bach-Peterson J (1980) Relatives of the impaired elderly: correlates of feelings of burden. The Gerontologist 20:649-655. https://doi.org/10.1093/geront/20.6.649

24. Chattat R, Cortesi V, Izzicupo F, Del Re ML, Sgarbi C, Fabbo A, Bergonzini E (2011) The Italian version of the Zarit Burden interview: a validation study. Int Psychogeriatr 23(5):797-805. https:// doi.org/10.1017/S1041610210002218

25. Derogatis LR, Lipman RS, Covi L (1973) SCL-90: an outpatient psychiatric rating scale preliminary report. Psychopharmacol Bull 9:13-28

26. Beck AT, Steer RA (1987) Manual for the Beck Depression Inventory. The Psychological Corporation, San Antonio

27. Beck AT, Steer RA (1993) Manual for the Beck Anxiety Inventory. The Psychological Corporation, San Antonio

28. Marin RS, Biedrzycki RC, Firinciogullari S (1991) Reliability and validity of the Apathy Evaluation Scale. Psychiatry Res 38(2):143162

29. Temple JB, Dow B (2018) The unmet support needs of carers of older Australians: prevalence and mental health. Int Psychogeriatr 30(12):1849-1860. https://doi.org/10.1017/S104161021800042X

30. Handels RLH, Sköldunger A, Bieber A, Edwards RT, GonçalvesPereira M, Hopper L, Irving K, Jelley H, Kerpershoek L, Marques MJ, Meyer G, Michelet M, Portolani E, Røsvik J, Selbaek G, Stephan A, de Vugt M, Wolfs C, Woods B, Zanetti O, Verhey F, Wimo A; Actifcare consortium (2018) Quality of life, care resource use, and costs of dementia in 8 European countries in a crosssectional cohort of the actifcare study. J Alzheimers Dis 66: 1027-1040. doi: https://doi.org/10.3233/JAD-180275.

31. Mast ME (2013) To use or not to use. A literature review of factors that influence family caregivers' use of support services. J Gerontol Nurs 39(1):20-28; quiz 29. https://doi.org/10.3928/0098913420121107-02

32. Chen YM, Thompson EA (2010) Understanding factors that influence success of home- and community-based services in keeping older adults in community settings. J Aging Health 22(3):267-291. https://doi.org/10.1177/0898264309356593

33. Zwingmann I, Dreier-Wolfgramm A, Esser A, Wucherer D, Thyrian JR, Eichler T, Kaczynski A, Monsees J, Keller A, Hertel J, Kilimann I, Teipel S, Michalowsky B, Hoffmann W (2020) Why do family dementia caregivers reject caregiver support services? Analyzing types of rejection and associated health-impairments in a cluster-randomized controlled intervention trial. BMC Health Serv Res 20(1):121. https://doi.org/10.1186/s12913-020-4970-8

34. Dello Buono M, Busato R, Mazzetto M, Paccagnella B, Aleotti F, Zanetti O, Bianchetti A, Trabucchi M, De Leo D (1999) Community care for patients with Alzheimer's disease and nondemented elderly people: use and satisfaction with services and unmet needs in family caregivers. Int J Geriatr Psychiatry 14(11): 915-924

35. Gaugler JE, Anderson KA, Leach MS, Smith CD, Schmitt FA, Mendiondo M (2004) The emotional ramifications of unmet need in dementia caregiving. Am J Alzheimers Dis Other Dement 19(6): 369-380. https://doi.org/10.1177/153331750401900605 
36. Vaingankar JA, Subramaniam M, Picco L, Eng GK, Shafie S, Sambasivam R, Zhang YJ, Sagayadevan V, Chong SA (2013) Perceived unmet needs of informal caregivers of people with dementia in Singapore. Int Psychogeriatr 25(10):1605-1619. https:// doi.org/10.1017/S1041610213001051

37. Mioshi E, Foxe D, Leslie F, Savage S, Hsieh S, Miller L, Hodges JR, Piguet O (2013) The impact of dementia severity on caregiver burden in frontotemporal dementia and Alzheimer disease. Alzheimer Dis Assoc Disord 27(1):68-73. https://doi.org/10. 1097/WAD.0b013e318247a0bc

38. Liu S, Liu J, Wang XD, Shi Z, Zhou Y, Li J, Yu T, Ji Y (2018) Caregiver burden, sleep quality, depression, and anxiety in dementia caregivers: a comparison of frontotemporal lobar degeneration, dementia with Lewy bodies, and Alzheimer's disease. Int
Psychogeriatr 30(8):1131-1138. https://doi.org/10.1017/ S1041610217002630

39. Poon E (2019) A systematic review and meta-analysis of dyadic psychological interventions for BPSD, quality of life and/or caregiver burden in dementia or MCI. Clin Gerontol 22:1-21. https:// doi.org/10.1080/07317115.2019.1694117

40. Etters L, Goodall D, Harrison BE (2012) Caregiver burden among dementia patient caregivers: a review of the literature. J Am Acad Nurse Pract 20(8):423-428. https://doi.org/10.1111/j.1745-7599. 2008.00342.x

Publisher's note Springer Nature remains neutral with regard to jurisdictional claims in published maps and institutional affiliations. 